\title{
Pearls \& Oy-sters: Neuro-Sweet disease presenting as ischemic stroke and aseptic meningitis
}

Alvin S. Das, MD,* Sarah E. Conway, MD,* Sebastian H. Unizony, MD, Marc A. Bouffard, MD, Natalia S. Rost, MD, and Nagagopal Venna, MD

Neurology ${ }^{\circledR}$ 2018;91:e2197-e2199. doi:10.1212/WNL.0000000000006628

\section{Pearls}

- Neuro-Sweet disease (NSD) should be considered in any patient with a history of Sweet syndrome who presents with neurologic symptoms.

- Cerebral infarction can be a manifestation of NSD and may be accompanied by a neutrophilic pleocytosis.

- NSD and its relapses may occur without any dermatologic findings.

\section{Oy-sters}

- Negative human leukocyte antigen should not deter the clinician from making the diagnosis of NSD, especially in non-Japanese patients.

- NSD may occur in a delayed fashion even after cutaneous Sweet syndrome is treated.

\section{Case presentation}

A 59-year-old man with JAK2V617F-positive polycythemia vera (PV), tubulointerstitial nephritis and uveitis syndrome, hypertension, and a remote history of skin biopsy-proven Sweet syndrome presented to the emergency department with 5 days of abnormal gait and diplopia as well as headache, subjective fevers, and diarrhea.

The patient's medical history was notable for panuveitis with retinal vasculitis diagnosed several years prior to his current presentation. Because of several relapses of his inflammatory eye disease, he was trialed on numerous immunosuppressive medications including cyclosporine, mycophenolate mofetil, and infliximab. Several weeks after one of his relapses, he developed fever, headache, malaise, arthralgias, night sweats, and a pustular rash on his forearms. Biopsy of the rash revealed a neutrophilic infiltrate and papillary dermal edema without vasculitis, consistent with Sweet syndrome. He was initiated on corticosteroids with improvement. Although an evaluation for underlying malignancy was initially negative, several years later, he was diagnosed with PV. Despite being maintained on hydroxyurea, he endorsed weight loss and fatigue 1 month prior to admission, raising the concern for uncontrolled PV.

On the day of presentation, the patient awoke with vertical diplopia and gait instability. Upon arrival to the emergency department, he was afebrile and well-appearing. Neurologic examination did not reveal any meningsmus, but was notable for a left hypertropia that worsened with downgaze and rightward gaze (consistent with a left fourth nerve palsy), left hand weakness, and an ataxic gait. Dilated funduscopy did not demonstrate signs of active uveitis. Laboratory workup was notable for neutrophilic leukocytosis $(28.1 \mathrm{~K} / \mu \mathrm{L}, 75 \%$ neutrophils $)$, hematocrit of $46.5 \%$, red blood cell count of $6.65 \mathrm{M} / \mu \mathrm{L}$, and a normal erythrocyte sedimentation rate. Brain
Correspondence

Dr. Das

asdas@mgh.harvard.edu

\footnotetext{
*These authors contributed equally to this work.
}

From the Department of Neurology (A.S.D., S.E.C., M.A.B., N.S.R., N.V.) and Department of Medicine, Division of Rheumatology (S.H.U.), Massachusetts General Hospital, and Department of Neurology, Brigham and Women's Hospital (A.S.D., S.E.C.), Harvard Medical School, Boston.

Go to Neurology.org/N for full disclosures. Funding information and disclosures deemed relevant by the authors, if any, are provided at the end of the article. 
MRI revealed scattered supratentorial infarcts in the left and right hemispheres (figure) and magnetic resonance angiography did not reveal vascular abnormalities. Repeat contrasted brain MRI 2 days later revealed 2 new strokes in the left corona radiata and left temporal periventricular white matter. Lumbar puncture demonstrated 485 nucleated cells/ $\mu \mathrm{L}$ (326 red blood cells $/ \mu \mathrm{L}$ ), of which $87 \%$ were neutrophils. CSF protein was $188 \mathrm{mg} / \mathrm{dL}$ and CSF glucose was $38 \mathrm{mg} / \mathrm{dL}$ (serum glucose was $79 \mathrm{mg} / \mathrm{dL}$ ). He was treated with broadspectrum antibiotics given the concern for bacterial meningitis. However, CSF cultures including fungal and tuberculosis cultures, herpes simplex virus nucleic acids, varicella-zoster virus immunoglobulin $M$ antibody, and blood cultures remained negative.

The patient underwent an extensive workup for immunemediated, hypercoagulable, and infectious disorders that can cause strokes. These investigations were negative or unremarkable including testing for antinuclear antibodies, antibodies against the extractable nuclear antigens (Ro, La, Sm, RNP), anti-double-stranded DNA antibodies, and antineutrophil cytoplasmic antibodies. Lupus anticoagulant, anticardiolipin antibodies, and anti- $\beta 2$-glycoprotein antibodies were negative as well. The human leukocyte antigen (HLA) B51 haplotypes B51, B54, and Cw1 were not identified. Repeat lumbar puncture demonstrated 203 nucleated cells $/ \mu \mathrm{L}(26,500$ red blood cells $/ \mu \mathrm{L})$ of which $79 \%$ were

Figure Admission MRI brain with and without contrast

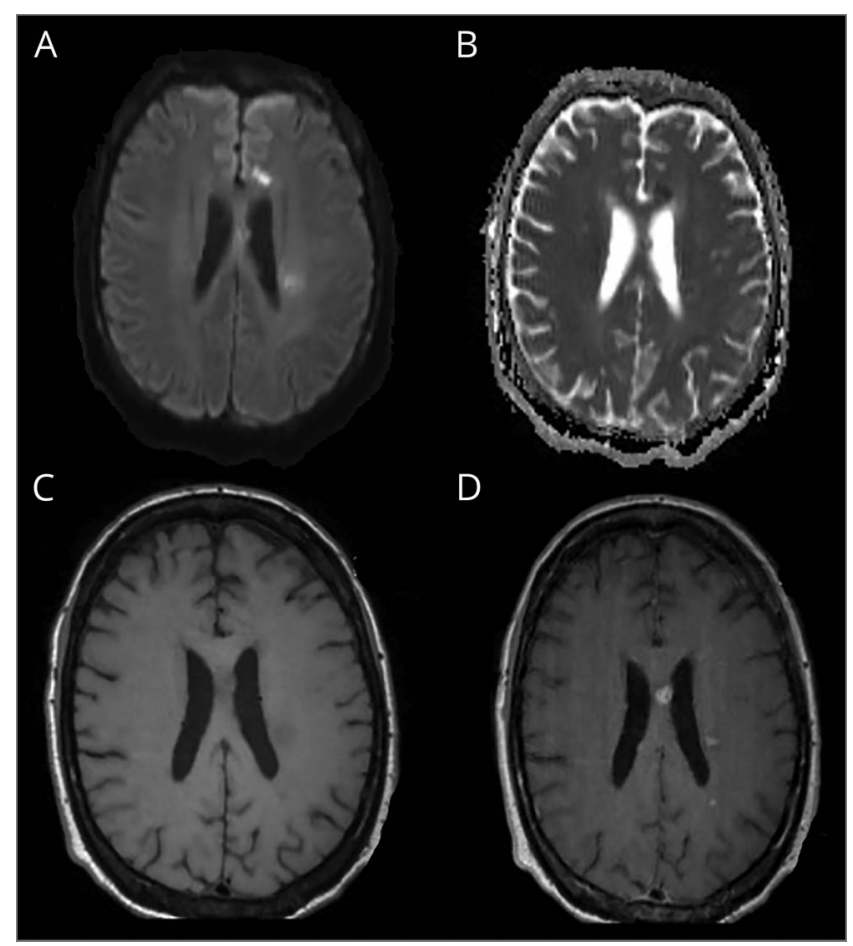

Brain MRI demonstrates multiple lesions that are bright on diffusionweighted imaging sequences $(A)$ and dark on apparent diffusion coefficient sequences, consistent with acute ischemia. T1 precontrast (C) and T1 postcontrast (D) images demonstrate several lesions that enhance, some of which are ischemic strokes. neutrophils. PET-CT showed splenomegaly related to the PV, but did not show any areas suspicious for inflammation or infection. A surface echocardiogram revealed a mobile linear echodensity $(9 \times 2 \mathrm{~mm})$ attached to the right coronary sinus concerning for a vegetation. With agitated saline contrast, the patient was also found to have a patent foramen ovale with right-to-left shunting at rest and with Valsalva maneuver. However, a transesophageal echocardiogram suggested that the echodensity was an incidental papillary fibroelastoma. Although papillary fibroelastoma is a known cause of stroke, it is not associated with meningitis; therefore, it was believed to be unrelated to the patient's presentation.

During the patient's hospital course, he did not develop any pustular rashes. He remained afebrile and no infectious organisms were identified, so antibiotics were discontinued. Ultimately, he received the diagnosis of possible neuro-Sweet disease (NSD) given his prior diagnosis of cutaneous Sweet syndrome. There was no alternative explanation for his presentation, including Behçet disease, which was ruled out based on the absence of recurrent oral ulcers. The patient underwent induction with IV corticosteroids followed by an oral prednisone taper. A repeat brain MRI 1 month later showed no new strokes or areas of inflammation, and a repeat lumbar puncture showed near resolution of his neutrophilic pleocytosis (4 nucleated cells $/ \mu \mathrm{L}$ ). Four months later, his neurologic examination was normal and he did not experience any relapses of his condition. Corticosteroids were tapered off, and the patient was started on adalimumab for remission maintenance.

\section{Discussion}

Sweet syndrome (acute febrile neutrophilic dermatosis) is a reactive dermatologic condition characterized by neutrophilic infiltration of the skin and other organs. NSD is a rare complication of Sweet syndrome and is manifested by recurrent neutrophilic meningoencephalitis, although parenchymal brain lesions have also been reported. ${ }^{1}$ Given its broad spectrum of neurologic complications and lack of prototypical features, NSD remains a challenging diagnosis to make. Herein, we report a patient with a history of cutaneous Sweet syndrome who developed an ataxic gait and left arm weakness caused by cerebral ischemia as a presenting feature of NSD. While there was no ischemic lesion visualized on brain MRI that explained his fourth nerve palsy, this was believed to be related to his meningitis. ${ }^{2}$ This patient initially developed cutaneous Sweet syndrome (a heralding sign of his hematologic malignancy), which was symptomatically suppressed by low-dose corticosteroids for several years, but then relapsed and manifested as NSD. The absence of an alternate etiology, CSF with neutrophilic pleocytosis, and marked response to steroids pointed to NSD as the cause of his meningitis and cerebral infarctions. While the exact trigger for development of NSD remained unclear, it is likely that it was precipitated by a slow steroid taper for his anterior uveitis the year prior. 
Cerebral infarction in NSD has been reported in 3 other cases previously. ${ }^{3,4}$ The latter 2 cases presented similarly to our patient, such that there was neutrophilic meningoencephalitis with stroke in the absence of cutaneous findings. In another case of NSD, ${ }^{5}$ the patient presented with headaches and fatigue and was found to have several areas of T2-weighted hyperintensities that enhanced with gadolinium. This patient did not have positive HLA testing, strokes, or a neutrophilic pleocytosis, but a brain biopsy revealed neutrophilic vasculitis consistent with NSD. Similar to our patient, NSD developed after his cutaneous Sweet syndrome had been treated. In the 3 aforementioned cases, 2 of the patients had infarcts as well as neutrophilic meningitis. The patient who did not have infarcts also did not have a neutrophilic pleocytosis. Although larger studies are needed to determine their true relationship, the presence of neutrophilic pleocytosis may portend more severe CNS involvement, such that small vessel vasculopathy develops leading to infarcts.

In the original report outlining NSD criteria, NSD relapses were common, and not always accompanied by cutaneous findings. ${ }^{1}$ In 1 case, encephalitis (characterized by recurrent MRI lesions) occurred frequently with most of these lesions being asymptomatic. This fact suggests that in a patient with cutaneous Sweet syndrome, there may already be silent, subclinical involvement in the CNS long before clinical symptoms develop. In our patient's case, the patient's fourth nerve palsy caused him to seek medical attention. Whether he had asymptomatic NSD prior to this is unclear. Given that NSD and its relapses can occur without cutaneous disease, it may be reasonable to monitor patients with Sweet syndrome by neurologic examination or imaging for development of NSD. Furthermore, once infection and other causes have been ruled out, it may be reasonable to consider empiric corticosteroids in a patient with Sweet syndrome who develops neurologic symptoms, without pursuing a brain biopsy.

Our patient did not meet full criteria for NSD on presentation. ${ }^{1}$ Supporting findings include a corticosteroidresponsive inflammatory meningitis as well as the absence of thrombotic vasculitis or Beçhet disease. However, he had negative HLA testing, and did not have dermatologic findings at the time of presentation. Based on our case presentation, we suggest modifying the criteria for dermatologic manifestations to include patients with any history of cutaneous
Sweet syndrome, not simply those who present with cutaneous features at the time of their NSD. Given that the criteria for NSD were originally described in Asian populations ${ }^{1}$ and relied on controls from healthy Japanese populations, ${ }^{6}$ HLA testing in non-Asian populations is unlikely to be helpful, due to the low prevalence of such HLA loci in non-Asian populations. ${ }^{7}$ Therefore, we also propose less reliance on HLA testing as a diagnostic criteria in non-Asian populations.

Our case highlights NSD as a cause of aseptic neutrophilic meningitis and ischemic strokes. NSD should be considered in patients with a history of Sweet syndrome who present with neurologic symptoms.

\section{Author contributions}

A.S. Das: study concept and design, acquisition of data, manuscript drafting. S.E. Conway: study concept and design, acquisition of data, manuscript drafting. S.H. Unizony: acquisition of data, critical revision of manuscript. M.A. Bouffard: acquisition of data, critical revision of manuscript. N.S. Rost: study concept and design, critical revision of manuscript. N. Venna: study supervision, critical revision of manuscript.

\section{Study funding}

No targeted funding reported.

\section{Disclosure}

The authors report no disclosures relevant to the manuscript. Go to Neurology.org/N for full disclosures.

\section{References}

1. Hisanaga K, Iwasaki Y, Itoyama Y; Neuro-Sweet Disease Study Group. Neuro-Sweet disease: clinical manifestations and criteria for diagnosis. Neurology 2005;64: $1756-1761$

2. García-Zamora M, Sánchez-Tocino H, Villanueva-Gómez A, Angles-Deza JM, PérezGutierrez E. Isolated fourth nerve palsy in tuberculous meningitis. Neuro-Ophthalmology 2016;40:40-43.

3. Mariën P, Tops W, Crols R, Jonkers R, De Deyn PP, Verhoeven J. Grammar disruption in a patient with Neuro-Sweet syndrome. Neurocase 2012;18:235-247.

4. Makimoto G, Manabe Y, Yamakawa C, et al. Two cases of possible neuro-sweet disease with meningoencephalitis as the initial manifestation. Neurol Int 2012; 4 :e5.

5. Charlson R, Kister I, Kaminetzky D, Shvartsbeyn M, Meehan SA, Mikolaenko I. CNS neutrophilic vasculitis in neuro-Sweet disease. Neurology 2015;85:829-830.

6. Mizoguchi M, Matsuki K, Mochizuki M, et al. Human leukocyte antigen in Sweet's syndrome and its relationship to Behçet's disease. Arch Dermatol 1988;124: 1069-1073.

7. González-Galarza FF, Takeshita LYC, Santos EJM, et al. Allele frequency net 2015 update: new features for HLA epitopes, KIR and disease and HLA adverse drug reaction associations. Nucleic Acids Res 2015;43:D784-D788. 


\section{Neurology}

\section{Pearls \& Oy-sters: Neuro-Sweet disease presenting as ischemic stroke and aseptic meningitis}

Alvin S. Das, Sarah E. Conway, Sebastian H. Unizony, et al.

Neurology 2018;91;e2197-e2199

DOI 10.1212/WNL.0000000000006628

This information is current as of December 3, 2018

\section{Updated Information \&} Services

References

Subspecialty Collections

Permissions \& Licensing

Reprints including high resolution figures, can be found at: http://n.neurology.org/content/91/23/e2197.full

This article cites 7 articles, 2 of which you can access for free at: http://n.neurology.org/content/91/23/e2197.full\#ref-list-1

This article, along with others on similar topics, appears in the following collection(s):

All Cerebrovascular disease/Stroke

http://n.neurology.org/cgi/collection/all_cerebrovascular_disease_strok e

All Medical/Systemic disease

http://n.neurology.org/cgi/collection/all_medical_systemic_disease Autoimmune diseases

http://n.neurology.org/cgi/collection/autoimmune_diseases

Infarction

http://n.neurology.org/cgi/collection/infarction

Meningitis

http://n.neurology.org/cgi/collection/meningitis

Information about reproducing this article in parts (figures,tables) or in its entirety can be found online at:

http://www.neurology.org/about/about_the_journal\#permissions

Information about ordering reprints can be found online:

http://n.neurology.org/subscribers/advertise

Neurology ${ }^{\circledR}$ is the official journal of the American Academy of Neurology. Published continuously since 1951, it is now a weekly with 48 issues per year. Copyright @ 2018 American Academy of Neurology. All rights reserved. Print ISSN: 0028-3878. Online ISSN: 1526-632X.

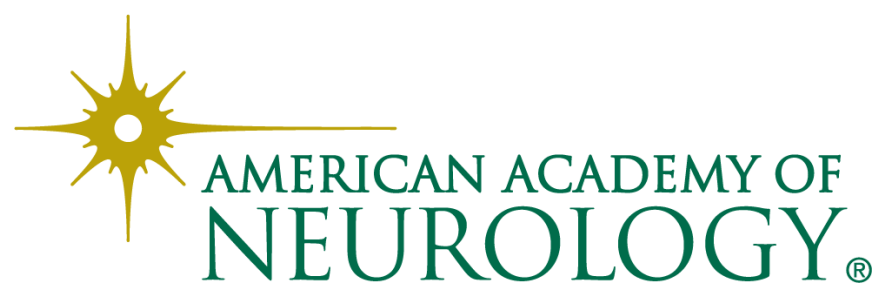

